Available online at: http://ijmt.ir/browse.php?a code $=A-10-236-2 \&$ sid $=1 \&$ slc lang=en

\title{
Sensitivity Analysis of Pile Supported Wharves against Directional Uncertainty of Earthquakes Using Fragility Curves
}

\author{
Mohsen Soltani ${ }^{1}$, Rouhollah Amirabadi ${ }^{2 *}$ \\ ${ }^{1}$ PhD student, University of Qom, Qom,Iran, M.Soltani1@stu.qom.ac.ir. \\ ${ }^{2}$ Assistance professor, University of Qom,Qom, Iran, r.amirabadi@qom.ac.ir.
}

\section{ARTICLE INFO}

Article History:

Received: 18 Feb. 2018

Accepted: 13 Mar. 2018

\section{Keywords:}

IDA

Fragility analysis

Pile-supported wharf

Directional uncertainty

\begin{abstract}
This paper aims to tackle an important uncertainty which extremely affects seismic performance of wharf structures in earthquake events. According to previous studies performed for structures on land, it is shown that structures on land are highly susceptible to unknown orientation of earthquakes called as the directional uncertainty. However, for marine structures, especially pile supported wharves, research efforts are rare to assess the effect of directional uncertainty of earthquakes on structural responses. Therefore, to show this effect on seismic performance of pile supported wharves, fragility analysis is performed based on methodology suggested by Pacific Earthquake Engineering Research Center (PEER) for the modeled pile supported wharf located in Maah-shahr port as a case study. As the first phase of this methodology, nonlinear static pushover analyses are performed for randomly chosen incident angles in order to quantitatively measure damage states suggested by marine design code. After damage states are obtained, IDA analyses are conducted in the selected incident angles to obtain nonlinear structural responses which are supposed to be used for fragility analysis as inputs. Finally, once fragility curves have been developed according to the last phase of PEER methodology, the more vulnerable direction(s) of wharf from those incident angles is represented.
\end{abstract}

\section{Introduction}

Traditional seismic design philosophy has constantly been revised due to sever damages that structures have experienced in high intensity earthquakes [1]. Recently, structures have been designed to prevent buildings from low-intensity damages and total collapse. However, it was perceived that there were other important factors like the economic loss due to downtime and repair cost after the 1994 Northridge and 1955 Kobe earthquakes [2-4]. Therefore, early forms of performance-based earthquake engineering (PBEE) which explicitly considered post-earthquake condition of structures were proposed (ATC-32, ATC-40, FEMA 273 , SEAOC vision 2000, and so on). One of the primarily restriction of this version was that the major portion of it was based on simplified techniques (such as prediction and definition of seismic hazard, methods of structural analysis, prediction of component, and structure performance) and did not consider new scientific advancement and information. Therefore, Pacific Earthquake Engineering Research Center (PEER) proposed a systematic methodology which seeks to thoroughly assess individual components related to earthquake engineering and to provide the probabilistic framework which combines these components for the seismic design and assessment of structures in conjunction with the most recent development in engineering science. Since the procedure of this framework is carried out based on a probabilistic manner, it can take uncertainties into account [5-6].

Along with the recent developments in design philosophy, one of the developments in earthquake engineering in analytical approaches has been Incremental Dynamic Analysis (IDA) method proposed by Cornell et al in 2002, which is well integrated into this probabilistic framework. The basis of IDA is a parametric analysis method to accurately calculate nonlinear structural responses under seismic loads. The procedure of IDA involves subjecting a structural model to ground motion time series, each scaled to multiple levels of intensity, in main principle directions of structure, thus producing one (or more) curve(s) of response parameterized versus intensity level [7]. However, apart from well integration of IDA into the framework, there are some uncertainties that affect the outcome of IDA [8]. Some of these uncertainties are structural, geotechnical, and seismic 
parameters measured for structures in form of one report released by (PEER) in 2006 [9], and various studies were carried out to measure effect of these uncertainties on marine structures. In 2007, $\mathrm{Na}$ et al investigated the effect of geotechnical uncertainty on PC1 berth damaged in Kobe earthquake event. In this study. It was shown that friction angle and shear modulus of soil contributed most to variability of structural responses [10]. In 2009, $\mathrm{Na}$ et al investigated the effect of soil property uncertainties on the wharf located in western part of United states, and they developed fragility curves for the wharf with and without considering effect of uncertainty. Finally, in this study, it was shown that the results obtained without considering the geotechnical uncertainties were underestimated [11]. In 2013, HeidaryTorkamani et al measured the effect of uncertainty in geotechnical and structural parameters of a pile supported by performing sensitivity analysis based on IDA approach. In this study, it was shown that friction angle and porosity of rock fill as the geotechnical parameters and dead load of the structure as the structural parameter affected seismic responses of the analytical approach most [12]. In addition to geotechnical and structural uncertainties, there are some seismic uncertainties with a considerable effect on structural responses. Although IDA deals with existing uncertainty in set of ground motions well, there is another type of seismic uncertainty which noticeably affects seismic demand especially in the inelastic zone. This uncertainty stems from existing uncertainty in unknown orientation of earthquake called as directional uncertainty. There are different investigations evaluated directional uncertainty for structures on land, especially. In 2010, Lagaros investigated the effect of directional uncertainty on IDA approach and integrated this approach with directional uncertainty introduced as Multicomponent Incremental Dynamic Analysis (MIDA) method. In this method, two components of earthquake were applied to structures with variation of incident angles from 0 to 360 degree to show variation of structural responses against different incident angles [13]. In 2017, Rupali et al used response spectrum method to evaluate demand response in different incident angles, from 0 to 90 degrees with an increment of 10 degrees, and the variation of responses against different incident angles was concluded [14].

According to the previous studies, the importance of considering uncertainties in performing a structural analysis is undeniable since the outcome of structural analysis is supposed to be used as an input for risk assessment of a structure by using fragility analysis. Therefore, the more reliable and accurate responses are obtained by the structural analysis, the more reliable results are concluded by fragility analysis. Recently, fragility analysis has been used as an efficient tool for the risk assessment of wharf structures. In 2011, in a dissertation, Shafieezadeh developed fragility curves for different components of one wharf, pile sections, pile-deck connection, relative movement of the wharf with respect to the land slide crane rail for twodimensional and three-dimensional nonlinear models. The results of analysis revealed that the relative movement of the wharf with respect to the land slide crane rail was the most susceptible component in the earlier step of fragility analysis. In addition, pile sections showed extreme vulnerability in high intensities [15]. In 2011, Chiou et al modeled port of Taiwan and developed fragility curves by Capacity Spectrum Method (CSM) in order to assess seismic performance of the port [16]. In 2012, Thompolous et al developed fragility curves for a typical pile supported wharf in Los Angles through proposing a methodology based on a nonlinear dynamic analysis [17]. In 2012, Yang et al developed two sets of fragility curves by performing nonlinear time-history analyses for two wharves with cranes in Los Angeles and California [18]. In 2014, Heydari-Torkamani et al analyzed a pile supported wharf by IDA and assessed seismic vulnerability of pile-supported wharves by developing fragility curves [19]. In 2016, BanayanKermani et al considered the pile supported wharf located in harsh environment of Persian Gulf. In this study, they induced the aging effect to the model and evaluated the effect of FRP layers as a common retrofit method on the damaged model by developing fragility curves [20]. In 2016, Kermani et al conducted a survey on the importance of fragility curves in seismic vulnerability assessment of pile-supported wharf and indicated an importunate need to develop the application of fragility curves for marine structures [21].

The previous studies show the importance of uncertainties in performing structural analysis which is the main basis of probabilistic framework of PBBE, and disregarding these uncertainties weaken the reliability and accuracy of output of this framework, which is the result of fragility analysis. Since less efforts are made for measuring the effect of directional uncertainty on seismic performance of marine structures, this paper aims to assess influence of directional uncertainty over seismic performance of a prevailing pile supported wharf by developing fragility curves. For this purpose, the four-phase PBEE probabilistic methodology of PEER is considered to perform fragility analysis step-by-step. Initially, Port of Maah-shar is selected as an input for the methodology. Then, to evaluate directional uncertainty, various incident angles with a constant increment are randomly selected. As the first phase of methodology, a pool of eleven ground motions is selected, and structural analyses i.e. pushover analyses and IDAs are performed in the selected incident angles as the second phase. When the required inputs for the fourth phase are determined, fragility curves are developed for the 
incident angles as the last phase of this framework. Finally, by comparing fragility curves, the more vulnerable direction(s) is concluded.

\section{2- PEER PBEE analysis methodology}

The PEER methodology with an iterative process includes 4 major steps as Figure 1: Hazard Analysis, Structural Analysis, Damage Analysis, and Loss Analysis. The results of each block are respectively represented as generalized variables: Intensity measure (IM), Engineering Demand Parameter (EDP), Damage measure (DM), and Decision Variable (DV). The iterative process of this methodology stems from finalizing an optimized input.

The relation between each block are mathematically represented by Total Probability Theorem Eq1.

$$
\begin{aligned}
& P[D V \mid O, D]=\iiint p[D V \mid D M] p[D M \mid E D P] \\
& p[E D P \mid I M] p[I M \mid O, D] d I M d E D P d D M
\end{aligned}
$$

Where $\mathrm{O}$ is Location of the structure, $\mathrm{D}$ is design of the structure, IM is intensity measure of earthquake site effects, EDP is engineering demand parameter as a measure of structural response, DM is measure of physical damage of various members, and DV is decision variable that is the performance parameter of interest such as report cost. The first step of this methodology is Hazard Analysis which produces on or more Intensity Measure (IMs). The IM which is typically represented by values of spectral acceleration or peak ground motion is used to show the strength or intensity of an earthquake. The second step is Structural Analysis. In this step, the desired structure is numerically modeled to predict EDPs in the given IMs. In fact, this step provides a link between IMs and EDPs by performing the structural analysis. The third step is Damage Analysis in which damage in structural and nonstructural analysis is predicted in accordance with EDPs, and damage measures (DMs), which are qualitatively defined by design codes, are physically identified in the numerical model. The relationship between DM and EDP is represented by fragility curves, which gives the probability of being in or exceeding a DM given a value of EDP. The last step of this methodology is Loss Analysis. This analysis mainly discusses the meaningful value for an owner or decision maker of the structure. This value includes direct pecuniary losses, casualties, and downtime [5]. In the following, a case study is considered to develop fragility curves through the procedure of PEER methodology. It is worth mentioning that the last phase of PEER methodology which is Loss Analysis is excluded since the aim of this paper is to assess the effect of directional uncertainty on pile supported wharves by developing fragility curves.

\section{2-Facility definition}

As the first phase of methodology, one structure has to be selected and designed. Therefore, wharf No.1 of Maah-shahr port located in Iran is considered as a case study (Figure $2-a$ ). This port is $20 \mathrm{~m} \times 45.6 \mathrm{~m}$ in plan (4@5 m span in transverse direction and 8@5.7 m span in longitudinal direction). In addition, it has 32 prestressed concrete (PC) vertical piles and 4 PC batter piles of class c. The batter piles inclination is 41 degrees comparing to the coast line. To model this wharf, SAP2000 software is used, and the 3D view of model is shown in figure 2-c [22]. In this model, properties of soil layers are shown in Table 1. Soil-pile interactions are modeled by Winkler's plastic springs (P-Y and T-Z curves) suggested by API standard [23]. Since the place where plastic hinge occurs is not obvious, plastic hinges are distributed and modeled on piles as Figure 2-e. In this figure, ductile plastic hinges are allowed to form at the cap piles and seabed where piles interact with soil. The modal analysis of this model reveals that the fundamental periods of model are $T_{x}=1.68 \mathrm{sec}$ and $T_{y}=1.63 \mathrm{sec}$ in strong and weak axes (i.e. Ox direction and Oy direction), respectively.

\section{3- Structural Analysis and Hazard Analysis}

The next phases of this methodology are followed by conducting Structural Analysis and Hazard analysis which are usually performed simultaneously. The structural analysis is frequently started by nonlinear

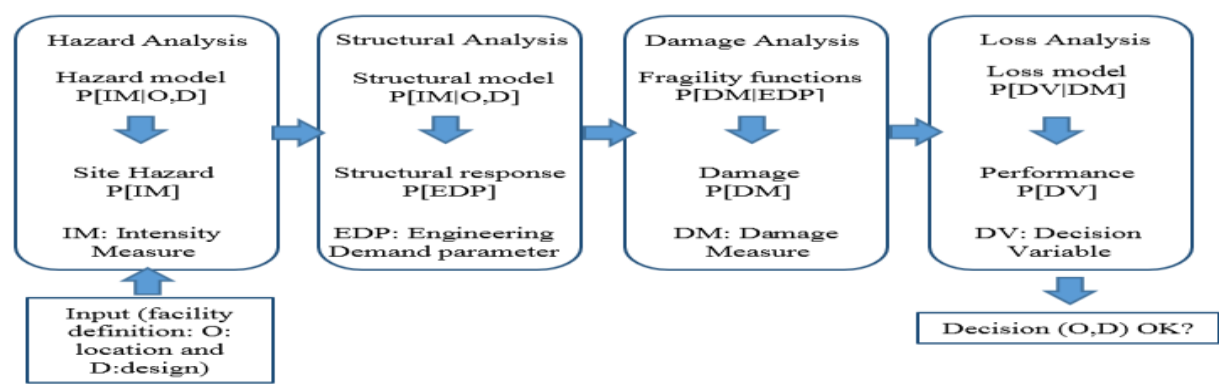

Figure 1. PEER (Pacific Earthquake Engineering Research center) PBEE analysis methodology [5] 
(a)

sea

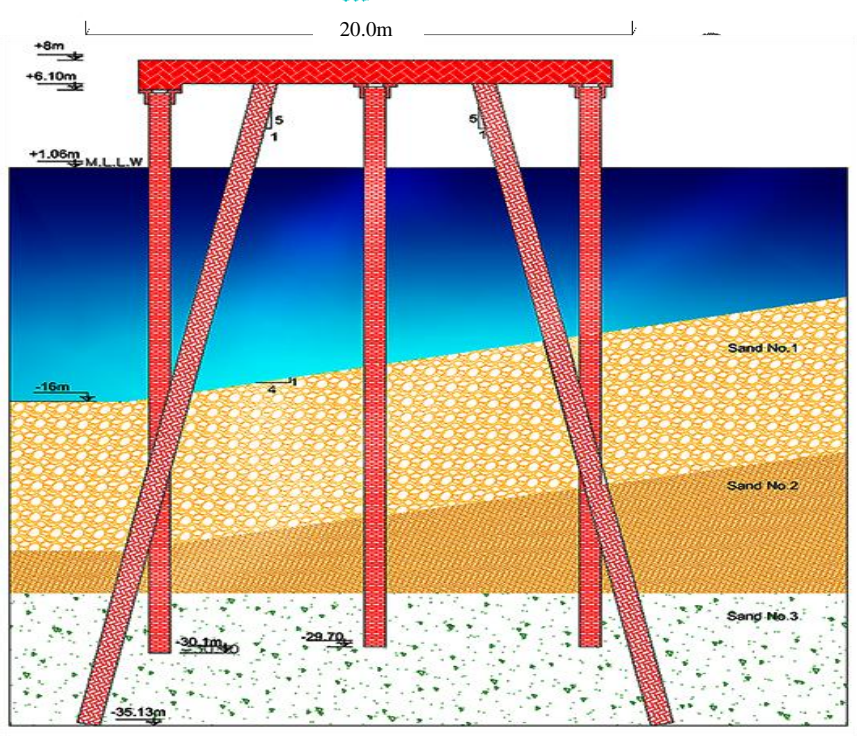

(c)
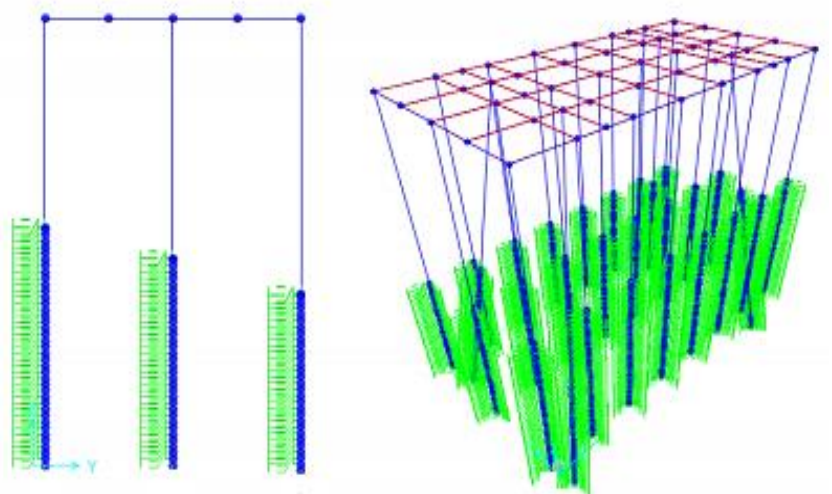

(b)

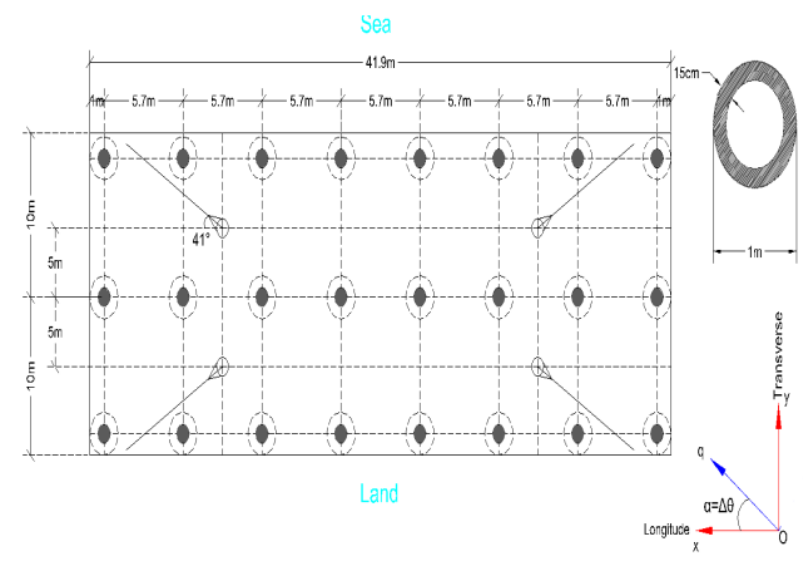

(d)

(e)
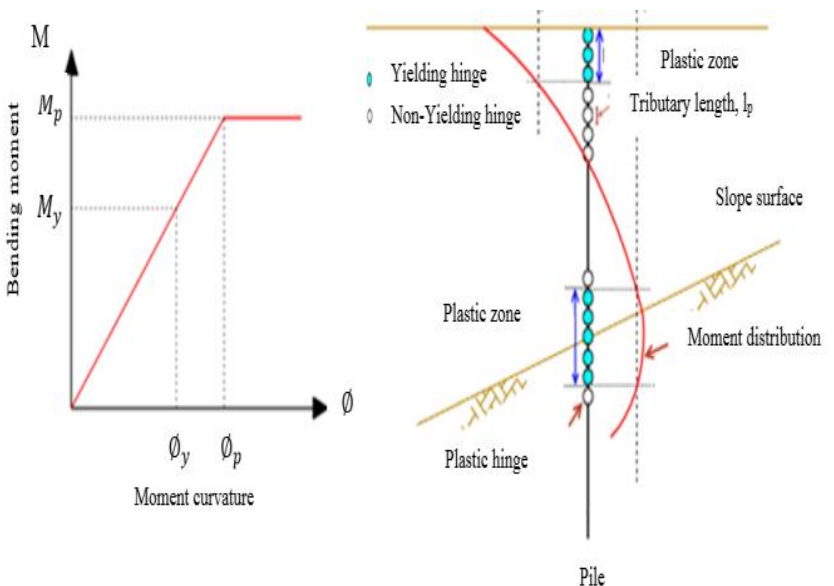

Figure 2. Maah-shahr wharf: (a) section (b) plan (c) Maah-shahr port in SAP2000 software. (d) moment-curvature curve of piles (e) distribution of plastic hinges on piles [19].

Table 1. Properties of soil layers in Maah-shahr port, wharf No.1.

\begin{tabular}{cccccc} 
No. & $\mathrm{H}(\mathrm{m})$ & $\mathrm{E}\left(\frac{\mathrm{Kg}}{\mathrm{Cm}^{2}}\right)$ & $\Upsilon_{\mathrm{d}}\left(\frac{\mathrm{Kg}}{\mathrm{Cm}^{2}}\right)$ & $\mathrm{C}\left(\frac{\mathrm{Kg}}{\mathrm{Cm}^{3}}\right)$ & $\Phi(\mathrm{deg})$ \\
\hline 1 & 10.5 & $40-55$ & $1.4-1.5$ & $0.15-0.2$ & 0 \\
\hline 2 & 1.0 & $80-160$ & $1.4-1.55$ & $0.3-0.6$ & 0 \\
\hline 3 & $23<$ & $350-450$ & $1.55-1.75$ & $1.5-2$ & 0
\end{tabular}

pushover analysis in order to determine damage measures required for the damage analysis. According to PIANC, damage measures are qualitatively represented as table 3 [24].
To obtain the quantities of damage measures based on PIANC suggestion, pushover analyses are performed along all directions from 0 to 180 with an increment of 22.5 degrees. These damage measures are specified in accordance with the occurrence of plastic hinges which are defined along $\mathrm{Ox}$ and $\mathrm{Oy}$ during the analyses. The results are shown along $\mathrm{Ox}$ and $\mathrm{Oy}$ to trace the trend of global instability in the structure better (Figure 3).

Table 2. Different damage states suggested by PIANC for piles of wharf structures [24].

\begin{tabular}{cccc} 
Damage states & Degree I: Serviceability & Degree II: Repairable & Degree III: Near Collapse \\
\hline $\begin{array}{c}\text { Pile (peak } \\
\text { response) }\end{array}$ & $\begin{array}{c}\text { Essentially elastic } \\
\text { response with minor or } \\
\text { no residual deformation }\end{array}$ & $\begin{array}{c}\text { Controlled limited } \\
\text { inelastic ductile response } \\
\text { and residual deformation } \\
\text { intending to keep the } \\
\text { structure repairable }\end{array}$ & $\begin{array}{c}\text { Ductile response near } \\
\text { collapse (double plastic } \\
\text { hinges may occur at one or } \\
\text { limited number of piles) }\end{array}$
\end{tabular}


(a)- Ox-direction

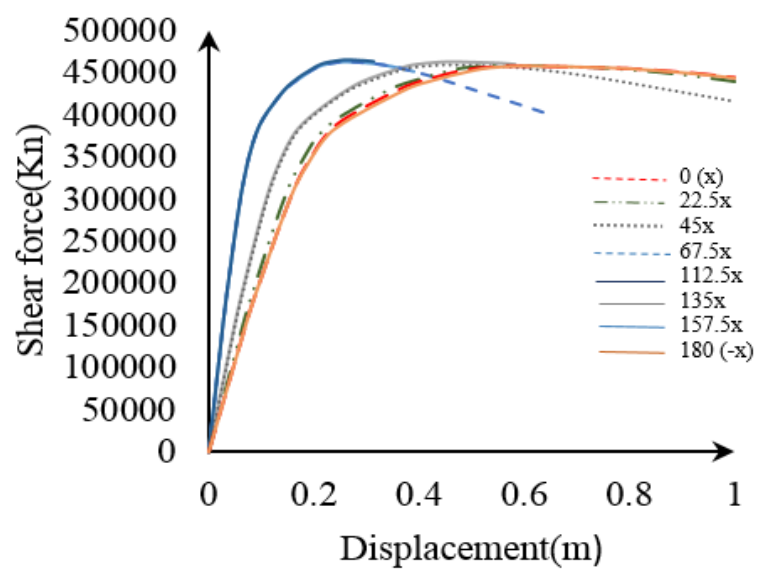

(b)- Oy-direction

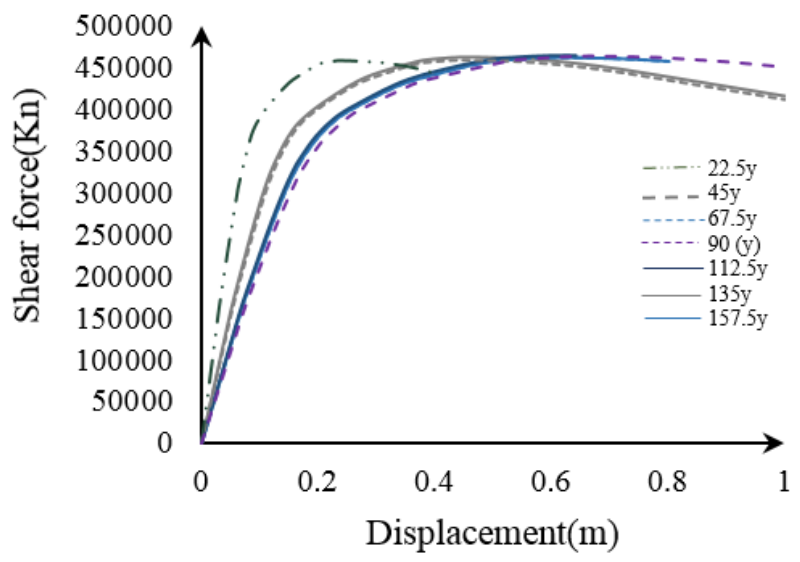

Figure 3. Pushover results of wharf No.1 in Maah-shahr port in (a) Ox-direction (b) Oy-direction.

After the pushover analyses, the structural analysis is continued by performing one dynamic analysis. According to previous studies, one of the common dynamic analysis which is well integrated to this frame work, especially when seismic uncertainty is under question, is IDA method [5]. There are two important steps in basis of IDA method. These are selecting a proper IM (Hazard Analysis) to scale selected ground motions and an appropriate EDP to develop IDA curves. There are different common IMs and EDPs for performing IDA method. The former is Peak Ground Acceleration (PGA), Peak Ground Velocity (PGV), and the $\xi=5 \%$ damped spectral acceleration at the structure first at the structure first mode Sa $(\mathrm{T} 1,5 \%)$. The latter is maximum base shear, nodal rotation, peak story ductility, peak roof drift, and the maximum peak inter story drift angle ( $\theta$ max) could be chosen [6]. For scaling selected ground motions, Amirabadi et al suggested that selecting Sa (T1, 5\%) as IM in IDA approach [25], and for developing IDA curves, PIANC is recommended to record peak response of piles as EDP. Therefore, after 11 time histories are selected as table 4 and Figure 4 from PEER database [26], they are scaled by Sa (T1,5\%). The major characteristic of scale factors is having structural responses changed from elastic to plastic zone. Then, IDA is performed for the incident angles as the pushover analyses, and IDA curves are developed in the monitored directions of $\mathrm{Ox}$ and Oy by the selected EDP. It is a common practice to perform IDA for strong and weak axes. To show the effect of directional uncertainty on IDA responses, IDA is initially performed for $0,90,112.5$, and 22.5 incident angles (Figure 5). Subsequently, they are summarized for different fractiles $(16,50$, and $84 \%)$ at each level of intensity (Figure 6). For the other incident angles, the same step is taken, and the summarized capacities obtained by IDA are displayed in Figure 8. According to this figure, the bearing capacity of structure depends on Oy direction for the incident angles around 90 degrees and on Ox direction for the incident angles around 0 and 180 degrees.

Table 3. The damage states for each direction $(\mathrm{cm})$

\begin{tabular}{|c|c|c|c|c|c|c|c|}
\hline \multirow{2}{*}{\multicolumn{2}{|c|}{$\begin{array}{c}\text { Damage } \\
\text { measures } \\
\text { Monitored } \\
\text { directions }\end{array}$}} & \multicolumn{2}{|c|}{$\begin{array}{l}\text { Serviceability } \\
\text { (I) }\end{array}$} & \multicolumn{2}{|c|}{$\begin{array}{l}\text { Repairable } \\
\text { (II) }\end{array}$} & \multicolumn{2}{|c|}{$\begin{array}{c}\text { Near } \\
\text { Collapse (III) }\end{array}$} \\
\hline & & Ox & Oy & Ox & Oy & Ox & Oy \\
\hline \multirow{9}{*}{ 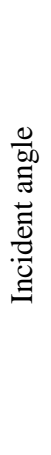 } & 0 & 14.95 & - & 45.73 & - & 76.51 & - \\
\hline & 22.5 & 14 & 6 & 42.5 & 18 & 71 & 30 \\
\hline & 45 & 10 & 10 & 31.5 & 31.5 & 53 & 53 \\
\hline & 67.5 & 5 & 14 & 16.5 & 41 & 28 & 68 \\
\hline & 90 & - & 16.72 & - & 43.36 & - & 70 \\
\hline & 112.5 & 6 & 14 & 16.5 & 39.25 & 27 & 64.5 \\
\hline & 135 & 10 & 10 & 32 & 31.77 & 54 & 53.5 \\
\hline & 157.5 & 6 & 14.4 & 17 & 41.5 & 29 & 69 \\
\hline & 180 & 16 & - & 46.85 & - & 78 & - \\
\hline
\end{tabular}

Table 4. The ground motion records selected from PEER database [26].

\begin{tabular}{ccccc} 
Event & Station & $\mathrm{M}$ & $\mathrm{R}(\mathrm{Km})$ & $\mathrm{PGA}(\mathrm{g})$ \\
\hline Northridge & Lake Hughes & 6.69 & 35.81 & 0.08 \\
\hline Cape Mendocino & Fortuna & 7.01 & 16.54 & 0.116 \\
\hline Loma perieta & Anderson dam & 7.1 & 24.32 & 0.247 \\
\hline Morganhill & San justo dam & 6.19 & 45.47 & 0.079 \\
\hline Sanfernando & $\begin{array}{c}\text { Pearblossom } \\
\text { Pump }\end{array}$ & 6.61 & 35.54 & 0.091 \\
\hline landers & $\begin{array}{c}\text { Desert Hot } \\
\text { Spring }\end{array}$ & 7.28 & 21.78 & 0.139 \\
\hline San fernando & Pasadena & 6.5 & 40 & 0.098 \\
\hline Manjil & Abbar & 7.37 & 12.55 & 0.359 \\
\hline Loma perieta & Fermont & 7.1 & 39.04 & 0.127 \\
\hline Loma perieta & Montary & 7.1 & 54.86 & 0.073
\end{tabular}


(a)

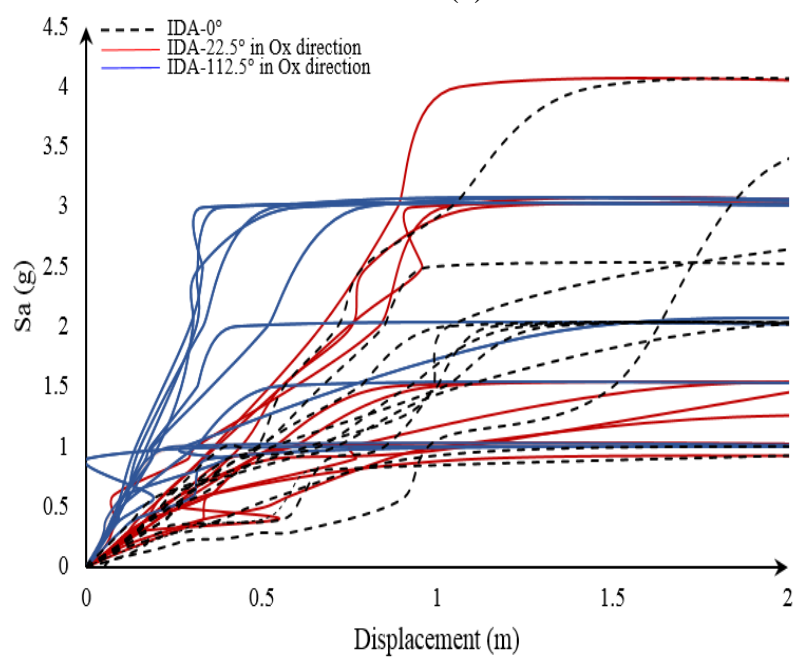

(b)

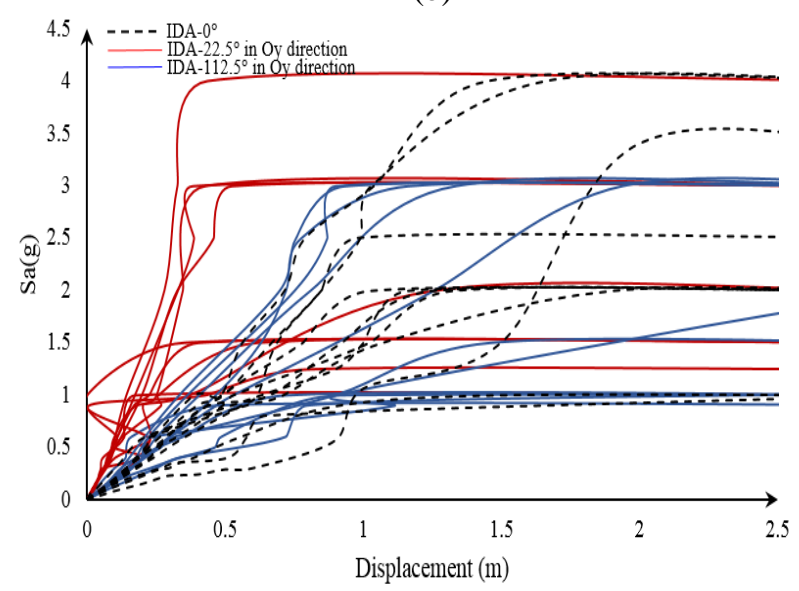

Figure 5. multi-recorded IDA (a) in 0, 22.5, and 112.5 degrees along Ox direction (b) in $0,22.5$, and 112.5 degrees along $O y$ direction.

$\left(a_{1}\right)$ - Ox direction

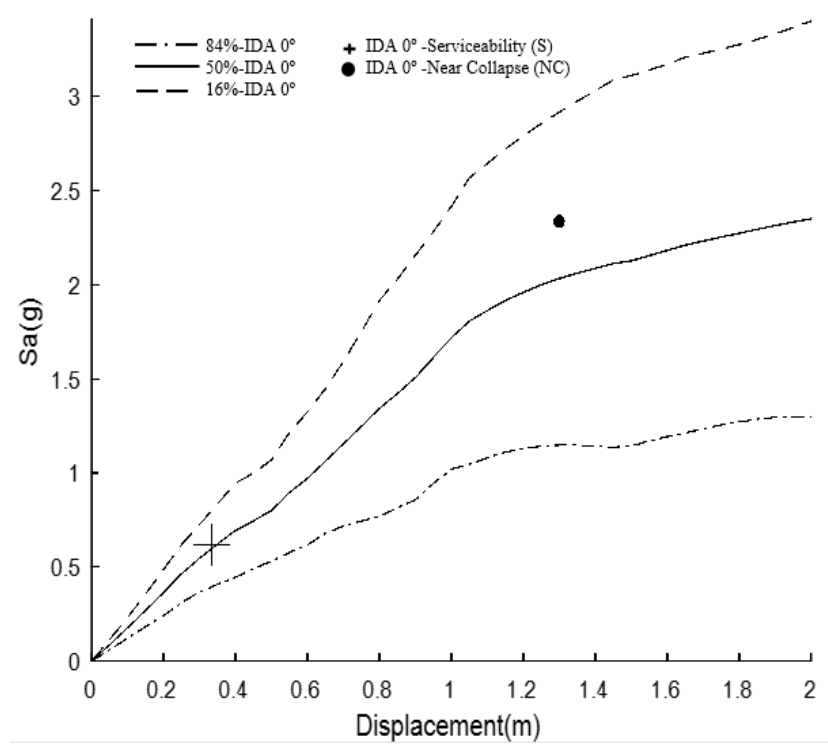

$\left(\mathrm{a}_{2}\right)-\mathrm{OY}$ direction

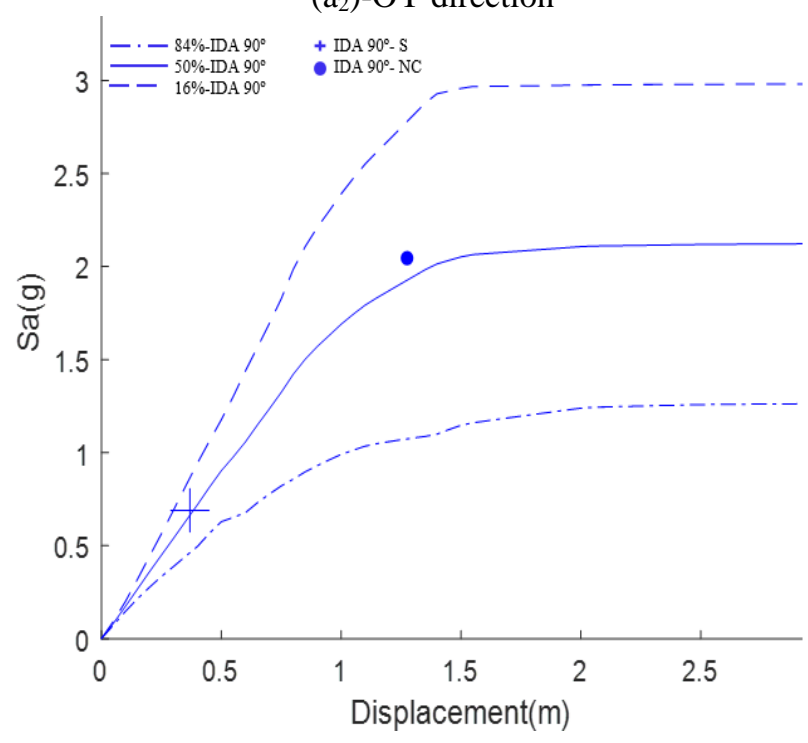

$\left(b_{1}\right)$-OX direction

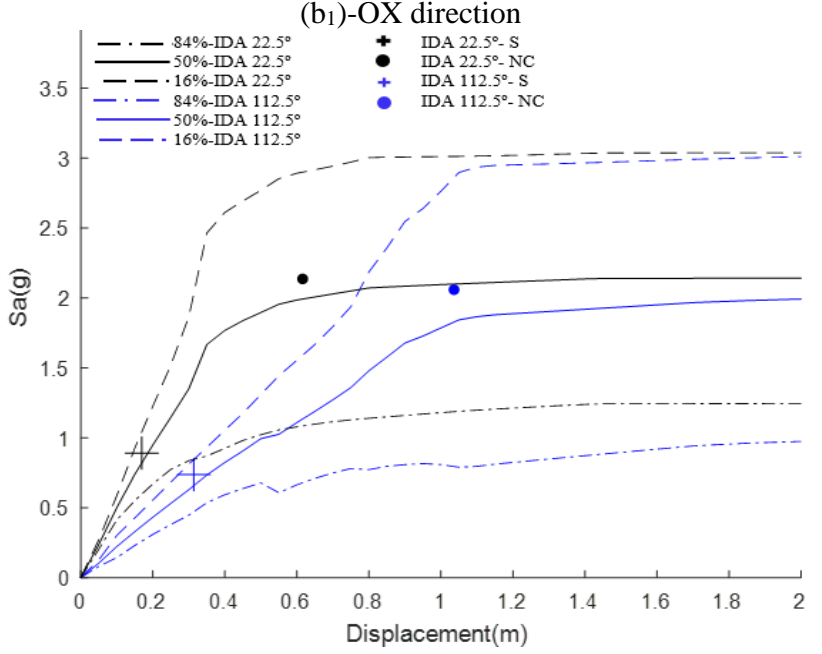

(b)-OY direction

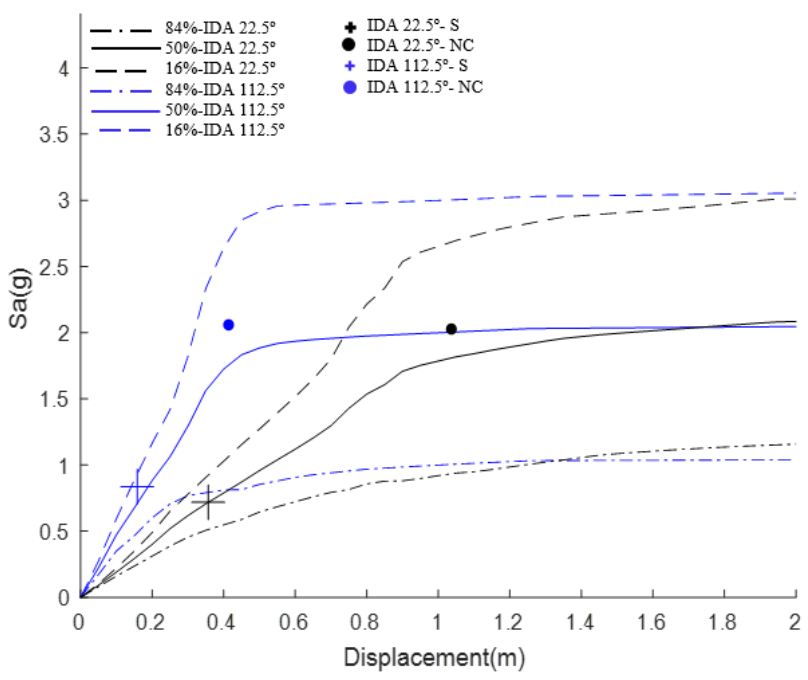

Figure 6. 16, 50, and $84 \%$ fractiles of IDA curves in Ox and Oy directions: (a) 0 degree (a) 90 degrees, $\left(b_{1}\right) 22.5$ degrees, $\left(b_{2}\right) \mathbf{1 1 2 . 5}$ degrees. 
(a)-OX direction

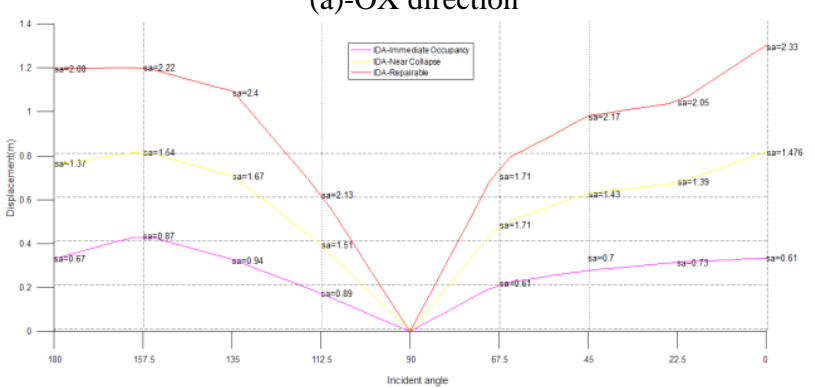

(b)-OY direction

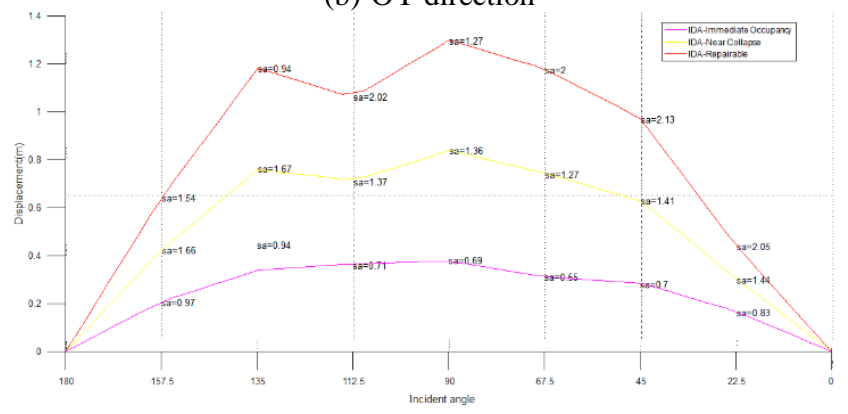

Figure 8. Summarized capacities of IDA in Ox and Oy directions for each incident angle.

\section{4-Damage Analysis (Fragility Analysis)}

To perform damage analysis, the outputs of previous phases i.e. EDPs and DMs are used for the fourth phase. In this phase, the conditional probability of wharf responses exceeding damage states of $\mathrm{s}_{\mathrm{i}}$ at a specific PGA level is obtained as fragility curves (Eq.2) [16].

$$
P[S>s \mid P G A]=P\left[X>x_{i} \mid P G A\right]=1-\Phi\left[\frac{\ln x_{i}-\lambda}{\zeta}\right]
$$

Where $\phi$ is normal cumulative distribution function, $\mathrm{x}_{\mathrm{i}}$ is the upper bound for $\mathrm{s}_{\mathrm{i}}(\mathrm{i}=\mathrm{I}, \mathrm{II}, \mathrm{III})$, and $\lambda$ and $\zeta$ are mean value $(\mu)$ and standard deviation $(\sigma)$ of sample population (x) in each scaled level (Eq.3, 4, and 5).

$\lambda=\ln \mu \frac{1}{2} \xi^{2}, \quad \zeta^{2}=\ln \left[1+\delta^{2}\right], \delta=\frac{\sigma}{\mu}$

As a common post processing of developed fragility curves, it is typical to use simplified fragility curves. These curves are typically expressed by lognormal distribution functions (lognormal CFD). Using lognormal CFD makes the application of fragility curves more convenient (Eq.6).

$$
F_{A}(a)=\int_{0}^{a} \frac{1}{\sqrt{2 \pi \zeta A a}} \exp \left[-\frac{1}{2}\left(\frac{\ln a-\operatorname{lnm} m_{A}}{\zeta A}\right)^{2}\right] d a
$$

Where $\mathrm{A}$ is the random variable of the PGA, $\mathrm{m}_{\mathrm{A}}$ is the median of $\mathrm{A}$, and $\zeta A$ is the logarithmic standard deviation of $A$. In figure 9, fragility curves are developed for each incident angle and shown for different damage states. According to this figure, the seismic performance of wharf is affected by directional uncertainty as the intensity of earthquakes increases, and in some incident angles plastic hinges occurred sooner than the others. For the serviceability damage state among these incident angles, the critical direction is 157.5 degrees where the probability of exceeding the damage state in a lower Sa is higher than the others in Oy direction. For the repairable damage state among these incident angles, the critical direction is 45 degrees where the probability of exceeding the damage state in a lower level of intensity is higher than the others in $\mathrm{Ox}$ direction. For the near collapse damage state, the critical direction among them is 0 degree which reaches to global instability in a lower level of intensity comparing to the others.

(a)

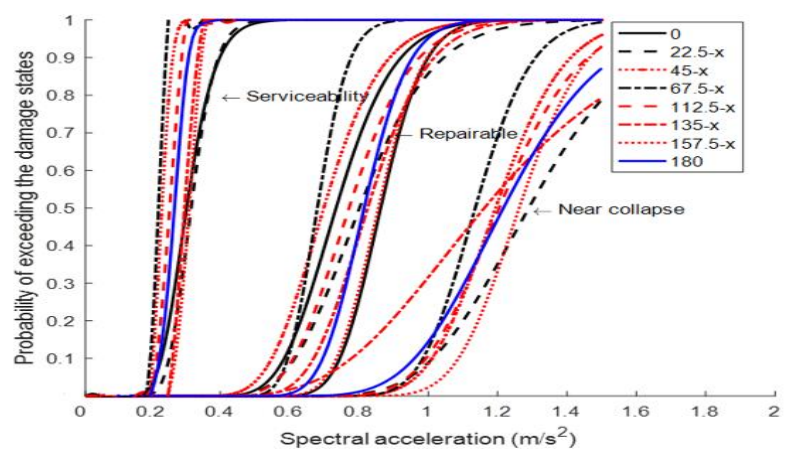

(b)

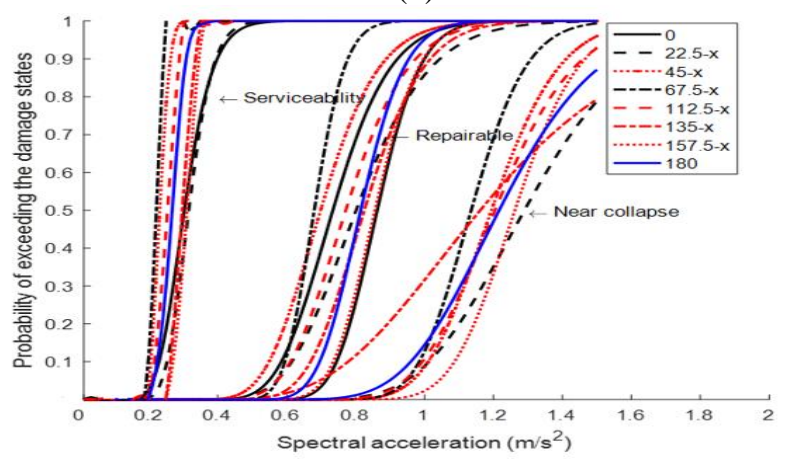

Figure 9. fragility curves in each incident angle for all damage sates (a) Ox direction (b) Oy direction.

\section{5-CONCLUSION}

In this paper, the systematic methodology of PEER PBEE analysis is adopted in order to assess seismic performance of the pile supported wharf of Maah-shar against directional uncertainty of earthquakes. According to step-by-step procedure of the four-phase methodology of PEER, 11 ground motions are selected, and pushover analyses and IDAs are performed to measure DMs and EDPs, respectively. To show the effect of directional uncertainty on seismic performance of the wharf, the third phase of this methodology is performed by developing fragility curves. By comparing fragility curves, it is shown that the severity of directional uncertainty reveals when the damage measures change from moderate damage to extensive damage. In addition, by using and comparing fragility curves for the selected incident angles, the critical directions among these incident angles for serviceability, repairable, near collapse damage states are 157.5 degrees in Oy direction, 45 degrees in $\mathrm{Ox}$ direction, and 0 degree with a high probability of occurrence, respectively. 


\section{6-REFERENCES}

1- Brunet, S., de la Llera, J.C., Jacobsen, A., Miranda, E. and Meza, C., (2012), Performance of port facilities in Southern Chile during the 27 February 2010 Maule earthquake. Earthquake Spectra, 28(S1), pp. S553S579.

2- SEAOC Vision 2000 Committee, (1995), Performance-Based Seismic Engineering, Report prepared by Structural Engineers Association of California, Sacramento, California.

3- Dong, Y. and Frangopol, D.M., (2016), Performance-based seismic assessment of conventional and base-isolated steel buildings including environmental impact and resilience. Earthquake Engineering \& Structural Dynamics, 45(5), pp.739-756.

4- Ferritto, J.M., (1997), Design Criteria for Earthquake Hazard Mitigation of Navy Piers and Wharves (No. NFESC-TR-2069-SHR). Naval Facilities Engineering Service Center Port Hueneme Ca.

5- Lee, W.K., and Billington, S.L., (2009) simulation and performance-based earthquake engineering assessment of self-centering post-tensioned concrete bridge systems, Pacific Earthquake Engineering Research Center (PEER), College of Engineering, University of California, Berkeley.

6- Vamvatsikos, D. and Cornell, C., (2002), Incremental Dynamic Analysis, Earthquake Engineering and Structural Dynamics, 491-514.

7- Dezvareh, R., (2019), Upgrading the Seismic Capacity of Pile-Supported Wharfs Using Semi-Active Liquid Column Gas Damper. Journal of Applied and Computational Mechanics.

8- Lee, T.H. and Mosalam, K.M., (2006), Probabilistic seismic evaluation of reinforced concrete structural components and systems, Pacific Earthquake Engineering Research Center (PEER) report, College of Engineering, University of California, Berkeley.

9- Pacific Earthquake Engineering Research Center, (2002), Estimation of Uncertainty in Geotechnical Properties for Performance-Based Earthquake Engineering, University of Washington.

10- Na, U.J. and Shinozuka, M., (2009), Simulationbased Seismic Loss Estimation of Seaport Transportation System, Reliability Engineering \& System Safety, Vol. 9, No.3, pp. 722-731.

11- Na, U.J., S.R., Chaudhuri, and Shinozuka, M., (2009), performance evaluation of pile supported wharf under seismic loading, Proc., TCLEE, p.10321041.

12- Torkamani, H., Bargi, K., and Amirabadi, R., (2013), Fragility curves derivation for a pile-supported wharf, International Journal of Maritime Technology, $1: 1-10$.

13- Lagaros, Nikos D., (2010), Multicomponent incremental dynamic analysis considering variable incident angle, Structure and Infrastructure Engineering, 77-94.
14- Rupali, J. and Jaiswal, J., (2017), Study of Effect of Seismic Excitation Angle for the Analysis of Regular and Irregular RC Frame, Mechanical and Civil Engineering, 80-83.

15- Shafieezadeh, A., (2011), seismic vulnerability assessment of wharf structure, in Civil and Environmental Engineering, Georgia Institute of Technology.

16- Chiou, J.S., Chiang, C.H., Yang, H.H, and Hsu, S.Y., (2011), Developing fragility curves for a pilesupported wharf, Soil Dynamics and Earthquake Engineering, Journal homepage: www.elsevier.com/locate/soildyn.

17- Thomopoulos, C., and Lai, C., (2012), Preliminary definition of fragility curves for pile supported wharves, Journal of Earthquake Engineering. 16(sup1): p.83-106.

18- Yang, C.-S.W., Desroches, R., and Rix, G.J., (2012), Numerical fragility analysis of vertical pilesupported wharves in the western United States, Journal of Earthquake Engineering. 16(4): p.579-594 19- Heidary-Torkamani, H., Bargi, K., Amirabadi, R., and McCllough, N.J., (2014), Fragility estimation and sensitivity analysis of an idealized pile supported wharf with batter piles, Soil Dynamics and Earthquake Engineering. 61-62(0): p. 92-106.

20- Banayan-Kermani, A., Bargi. Kh., and HeidaryTorkamani. H., (2016), Seismic performance assessment of pile-supported wharves retrofitted by carbon fiber-reinforced polymer composite considering aging effect, Advances in Structural Engineering. DOI: 10.1177/1369433216630187.

21- Kermani. A, and Bargi. K., (2016), Fragility curves: a powerful tool for seismic vulnerability assessment of pile-supported wharves, International Journal of Science and Engineering. ISSN:2454.

22- SAP2000 V19.0, (2017), CSI Analysis Reference Manual for SAP 2000, Computers and Structures, Inc., Berkley, California.

23- American Petroleum Institute (API), (2000) Recommended practice for planning, designing, and constructing offshore platforms: API recommended practice $2 A(R P 2 A), 17^{\text {th }}$ ed. Washington, DC: American Petroleum Institute.

24- PIANC., (2001), Seismic Design Guidelines for Port Structures, Permanent International Navigation Association, A.A. Balkema Publishers, Rotterdam, The Netherlands.

25- Amirabadi, R., Bargi, K., Dolatshahi Piroz, M., Heydari Torkamani, H., Mccllough, N., (2012), Probabilistic seismic demand model of PEER-PBEE framework for pile and deck structure, International Journal of Civil and Structural Engineering.

26- Pacific Earthquake Engineering Research Center (PEER), (2107) Data from: PEER Ground Motion Database. Retrieved from http://ngawest2.berkeley.edu/users/sign_in. 